\title{
MORAL E DIREITO NAS TANNER LECTURES DE HABERMAS: UM MODELO PROCESSUAL DE MORALIZAÇÃO DO DIREITO
}

\author{
MORALS AND LAW IN HABERMAS'S “TANNER LECTURES”: A \\ PROCEDURAL MODEL OF THE MORALIZATION OF LAW
}

\author{
DELAMAR JOSÉ VOLPATO DUTRA \\ (UFSC / Brasil) $)^{l}$
}

\begin{abstract}
RESUMO
Pode-se defender que o positivismo se caracteriza, principalmente, pela tese da separação entre direito e moral. Com tal tese, o direito passa a ser explicado seja de forma completamente independente de qualquer teoria moral seja, em sua quintessência, por algum tipo de positivismo moral, como aquele defendido por Kelsen. Habermas, um dos críticos do positivismo, restabelece a conexão entre direito e moral, operando desse modo o que se poderia chamar de moralização ou remoralização do direito. Pretende-se apresentar, neste estudo, o modelo das Tanner Lectures [1986]. Neste texto, Habermas defende uma relação de subordinação do direito à moral; não obstante, uma subordinação processual, e não de conteúdos.
\end{abstract}

Palavras-chave: Habermas. Positivismo jurídico. Tanner Lectures.

\begin{abstract}
It's possible to sustain that the legal positivism is defined by the separation thesis between law and morality. According to such a thesis the legitimacy of law could be explained in a completely different way of that of morality. Habermas is considered a critical of positivism, as he restores the mentioned connection between law and morality. In this paper it's aimed to present the model of this relation in the Tanner Lectures [1986].
\end{abstract}

Keywords: Habermas. Legal positivism. Tanner Lectures.

\section{A relação entre moral e direito}

O presente texto parte da aceitação da tese da conexão entre moral e direito, o que parece ser comum a vários filósofos e juristas. O ponto relevante, não obstante, é como relacionar adequadamente os dois predicados. Pretende-se fazer tal análise a partir da obra de Habermas sobre o assunto.

De fato, tal problemática encontra um lugar privilegiado de tratamento na obra de Habermas, pois nela aparece essa tensão da relação entre a normatividade jurídica e moral, já 
que, por um lado, ele afirma: "uma ordem jurídica só pode ser legítima, quando não contrariar princípios morais. Através dos componentes de legitimidade da validade jurídica, o direito adquire uma relação com a moral"2, e, por outro lado, recusa fortemente que a justificação do direito seja simplesmente subordinada à justificação moral: “entretanto, essa relação não deve levar-nos a subordinar o direito à moral, no sentido de uma hierarquia de normas"3.

Com relação ao tratamento da questão feito por Habermas há quem o acuse de encapsular a moral no direito ${ }^{4}$, como há quem sustente que a ética desapareceu do empreendimento de $\mathrm{FG}^{5}$ ou que "a ética discursiva encontra-se tout court substituída pela democracia" . Seja como for, o ponto está em que, por um lado, o direito não pode contrariar a moral, e, por outro lado, não pode ser subordinado no sentido de a moral ser hierarquicamente superior.

A questão de como relacionar direito e moral é recorrente e fundamental no empreendimento filosófico de Habermas. Tal pode ser visto no prefácio a FG, no qual, comentando os capítulos III e IV da obra mencionada, ele afirma: "convém notar, todavia, que atualmente eu não determino mais a relação complementar entre moral e direito seguindo a linha traçada nas Tanner Lectures"7 . No contexto desta citação, ele dá uma indicação indireta do conteúdo da passagem na nota 4 que ele apõe à mencionada alusão. Ele diz que Apel seguiu um acesso por demais normativista $^{8}$. Que tal afirmação seja importante se mostra, por exemplo, pela reação de Apel a ela, que o levou a escrever mais de cem páginas sobre o assunto em Auseinandersetzungen in Erprobung des transzendentalpragmatischen Ansatzes ${ }^{9}, 1998$.

Assim, o esclarecimento do papel da moral na racionalidade do direito na obra de Habermas parte da necessidade de elucidar a mudança operada das Tanner Lectures para FG. Parece que a mudança com relação às Tanner Lectures tenha sido uma revisão do acento demais normativista do papel da moral na sua relação complementar ao direito. No entanto, tal afirmação ainda é carente de um estudo melhor, haja vista o debate que tal problemática suscitou.

A matéria é mesmo problemática, pois, se dermos crédito ao que é explicitamente tratado por Habermas em FG, parece que ele dispensa a moral de qualquer relação com a normatividade jurídica que agora ganha fórum de independência, sendo que o direito passa a ser requisitado como uma espécie de guardião da moral, dado seu caráter coativo: "quando não se identifica mais a pretensão de legitimidade das normas do direito, ou seja, a sua 'justeza', com a pretensão à justiça moral, é possível deixar aberta a questão subseqüente da fundamentação moral do direito enquanto tal"10; ou seja, "a filosofia não necessita de argumentos morais para demonstrar que é 
recomendável organizar nossa convivência com os meios do direito [...] pois bastam argumentos funcionais" ", sendo tal formulação válida mesmo para estabelecer com segurança condições morais de respeito mútuo. No entanto, não fica claro se, assim, uma possível justificação do direito ocorreria tão somente na medida em que ele complementasse os déficits da moral como sistema de ação, tal como explicitado pela tese da complementaridade, ou se ele realmente ganha autonomia normativa. Ora, não parece ser o caso que ele tenha sua normatividade subordinada à moral, visto que Habermas recusa um caráter subalterno da normatividade jurídica em relação à moral, nem parece ser o caso que a autonomia normativa vá ao ponto de não portar mais qualquer conexão com a moral. Portanto, a mencionada nota 4 assinala um outro modo de compreensão.

\section{Weber: a racionalidade própria do direito}

O pensamento de Weber é central para as teses de Habermas. Isso pode ser facilmente comprovado pelo papel importante que ele desempenha na Teoria da ação comunicativa, bem como nas Tanner Lectures, não sendo menor a sua posição em FG. De fato, Habermas dedica o cap. II da Teoria da ação comunicativa a Weber e parte do interlúdio primeiro. Das seis partes das Tanner Lectures, a primeira é consagrada a Weber, bem como porção do cap. II de FG, de sorte que Weber, dentre outros, é um autor seminal de seu pensamento. Habermas analisa-o de diversos modos, imputando a ele certas apreciações do direito que mudam a depender do período em que escreve. As características apontadas na Teoria da ação comunicativa não parecem ser as mesmas das Tanner Lectures, haja vista que naquele texto são destacadas a positividade, a legalidade e a formalidade, ao passo que neste ele chama a atenção para o caráter sistemático do direito, para o caráter geral e abstrato da lei e para a segurança que o sistema jurídico oferece. As características apontadas podem ser facilmente encontradas no texto weberiano sobre a sociologia do direito, bem como em outras referências ao mesmo, como aquela feita por Luhmann no início de sua sociologia jurídica, a qual aponta, inclusive, para um dos pontos da análise de Habermas. Luhmann sugere como características weberianas do direito a positividade, a segurança e a formalidade. Ademais, Habermas salienta a importância de Weber ter assinalado o caráter racionalizador do direito em relação a outros modos de organização social, uma consideração, aliás, que não passou despercebida por outros teóricos do direito, como Luhmann:

ethic@-Florianópolis, v. 10, n. 3,p.13-37, Dez. 2011. 


\begin{abstract}
Weber, por seu lado, visa a um desenvolvimento que crescentemente diferencia e autonomiza o complexo das normas de direito, ou seja, os libera do entrelaçamento com outras estruturas sociais, precisando-as no interesse de funções específicas. Desta forma são superados elementos do arbítrio pessoal na aplicação do direito (justiça de Cádi) e vinculações a costumes e concepções de moral próprias a pequenos grupos, transmitidas por tradição e incompreensíveis para estranhos. Apenas assim se torna possível basear investimentos amplos e a longo prazo em possibilidades calculáveis, juridicamente asseguradas de forma confiável ${ }^{12}$.
\end{abstract}

No entanto, não se pense encontrar tal segurança - que Luhmann nomina expectativa - no nível dos conteúdos, mas naquele dos procedimentos. Dessa posição, como se verá, Habermas não discordará em absoluto, mas só relativamente, na medida em que o procedimento por ele proposto - o discursivo - intentará atenuar o elemento volitivo da decisão para que o resultado não se caracterize como um decisionismo, posição que ele reputa criticável em Schmitt, por exemplo. O tema comum de boa parte das análises, tendo como ponto de partida Weber, feitas por Habermas, reside em apontar e criticar o caráter positivista do procedimento proposto e o caráter decisionista ${ }^{13}$ dos produtos dele oriundos. Em momentos diversos Habermas combate esses dois aspectos.

Cabe esclarecer que tais análises feitas pelo autor das Tanner Lectures não têm a função de interpretar Weber fielmente. O que Habermas quer, na verdade, é construir uma posição teórica em contraste com a qual ele desenvolverá a sua própria posição, e Weber é usado em tal reconstrução. Até porque o método reconstrutivo de Habermas utiliza explicitações de certas condições da racionalidade anteriormente feitas por outras teorias ${ }^{14}$, já que as reconstruções racionais "apreendem sistemas anônimos de regras que podem ser seguidas por qualquer sujeito desde que esses tenham adquirido a competência correspondente no uso das regras" ${ }^{15}$. Elas

\footnotetext{
referem-se a um saber pré-teórico de tipo universal, a uma capacidade universal (...). Quando o saber pré-teórico que há de se reconstruir representa uma capacidade universal, quer dizer, uma competência (ou sub-competência) cognoscitiva, lingüística ou interativa, o que começa sendo uma explicação de significados tem como meta a reconstrução de competências da espécie ${ }^{16}$.
}

Portanto, elas têm uma pretensão especialíssima de descrever e tornar explícitas estruturas profundas de competência. O método que ele utiliza para isso é aproveitar parte das teorias já existentes sobre tais competências ${ }^{17}$. Embora Habermas continue um crítico de conhecimentos determinados, como a sociologia de Luhmann ou o positivismo nas ciências sociais e jurídicas, ele consegue vislumbrar momentos da racionalidade comunicativa nas teorias que analisa, como é o caso de certas teorias sociológicas, a exemplo do próprio Weber ou da filosofia analítica da ethic@-Florianópolis, v.10, n.3,p.13-37, Dez. 2011. 
linguagem. Esse caráter do seu pensamento não anula a determinação de sua teoria como sendo crítica, ainda que tal determinação esteja em um outro nível, visto que o que ele intenta, antes de tudo, é dar conta da fundamentação da teoria crítica. Nesse sentido, com a teoria da racionalidade comunicativa alcançada pelo método reconstrutivo, Habermas amplia os temas da teoria crítica e encontra um novo paradigma explicativo que permite

\footnotetext{
simultaneamente fornecer uma solução para o ancoramento real da emancipação na configuração social atual e estabelecer um parâmetro crítico para avaliar tanto o conhecimento produzido quanto situações sociais concretas, já que o potencial comunicativo inscrito na vida social jamais se realiza plenamente ${ }^{18}$.
}

Como se verá adiante na análise weberiana do conceito de ação e de legitimidade, Habermas buscará mostrar como na teoria weberiana operam determinações da racionalidade que permanecem ocultas no texto do autor analisado, mas que são importantes para a construção da sua própria posição.

Feita a observação acima, é conveniente retomar alguns aspectos da análise weberiana do direito para se compreender melhor esses pontos. Segundo Weber, a legitimidade é uma crença no dever-ser de uma norma ${ }^{19}$. No caso do direito, como ordem jurídica, ele está garantido externamente pela probabilidade da coação (física ou psíquica) ${ }^{20}$, já que a legalidade é uma forma de legitimidade sobre a qual se acrescenta a coerção, o que permite que ela seja classificada como possível de ser legitimada com relação a fins.

O conceito de coerção remete ao conceito de poder, cuja definição ele apresenta do seguinte modo: "poder significa a probabilidade de impor a própria vontade, dentro de uma relação social, mesmo contra toda a resistência e qualquer que seja o fundamento desta probabilidade" 21 . O poder, quando revestido de legitimidade, é obedecido. A obediência aos ditames do poder metamorfoseia-o em dominação, sendo a disciplina uma obediência automatizada. Uma associação de dominação é política quando pode contar com a coerção externa, portanto, com o poder. O Estado é um instituto político que consegue manter com êxito o monopólio legítimo do uso da força física para sustentar a ordem, a qual, ainda que não seja o modo normal de manutenção das associações políticas, é o seu meio específico, a sua última ratio.

Essa consideração de Weber, por um lado, unifica poder e direito, enquanto uma pura forma coercitiva despida de conteúdo, e, por outro lado, separa essa forma de qualquer conteúdo 
que lhe possa ser acrescentado. Ou seja, a definição de direito, como acima visto, une-o, intrinsecamente, com o poder, ou seja, com a coerção, despojando-o de qualquer conteúdo. Mesmo a legitimidade jurídica, aqui, é privada de conteúdo, pois ela é formal, remetendo ao procedimento de sua criação e à crença de que esse procedimento é legítimo. Nas palavras de Weber,

\begin{abstract}
não é possível definir uma associação política - inclusive o 'Estado' - assinalando os fins da 'ação da associação' [...] não existiu nenhum fim que ocasionalmente não haja sido perseguido pelas associações políticas; e não houve nenhum [...] que todas essas associações tenham perseguido. Só se pode definir, por isso, o caráter político de uma associação pelo meio [...] que sem ser-lhe exclusivo é certamente específico e para a sua essência indispensável: a coação física ${ }^{22}$.
\end{abstract}

Portanto, não há, para ele, um direito substancial que possa receber o nome de direito, independentemente de um aparato normativo. Daí a sua filiação ao positivismo, pois este se caracteriza menos pela afirmação de que o direito é o direito positivo e mais pelo que subjaz a essa afirmação, a saber, que o direito é o direito positivo porque, em última análise, ele não passa de uma forma coercitiva ${ }^{23}$. A formulação de Kelsen sobre o direito positivo ajuda a compreender melhor a posição de Weber:

\begin{abstract}
o Direito positivo é essencialmente uma ordem de coerção. Ao contrário das regras do direito natural, as suas regras derivam da vontade arbitrária de uma autoridade humana e, por esse motivo, simplesmente por causa da natureza de sua fonte, elas não podem ter a qualidade da auto-evidência imediata. O conteúdo das regras do Direito positivo carece da necessidade 'interna' que é peculiar às regras do direito natural em virtude de sua origem [...] a doutrina que declara a coerção como característica essencial do Direito é uma doutrina positivista e se ocupa unicamente com o Direito positivo ${ }^{24}$.
\end{abstract}

Para Kelsen, conseqüentemente, o sistema do direito natural tende a ser um sistema estático, o que determina um caráter conservador ao mesmo, ao contrário do direito positivo que é um sistema dinâmico em razão de se reconhecer como um produto da atividade humana. Aliás, a afirmação de FG de que a forma jurídica não é fundamentada moralmente ${ }^{25}$ honra a seu modo essa formulação positivista do direito.

Tal consideração permite a Weber oferecer uma concepção de legitimidade da legalidade de caráter formal ${ }^{26}$, isto é, neutra com relação a conteúdos, bem como uma concepção de direito que corresponde a essa neutralidade. Nesse sentido, Weber é partidário de uma legitimidade estritamente processual, já que uma norma portará um índice de crença na sua legitimidade pelo motivo principal do procedimento legal pelo qual passou: "a forma de legitimidade hoje mais 
corrente é a crença na legalidade: a obediência a preceitos jurídicos positivos estatuídos segundo o procedimento usual e formalmente correto" ${ }^{27}$. Dessa forma, segundo ele, o que caracteriza a dominação legal é que "qualquer direito pode ser criado e modificado mediante um estatuto sancionado corretamente quanto à forma" ${ }^{, 2}$. Sendo a legitimidade uma crença, nada impede que normas distintas e mesmo contraditórias possam ser consideradas como válidas ${ }^{29}$. Sendo assim, pode-se ver como Weber apresenta um conceito de direito, bem como de poder, neutro com relação a qualquer determinação de legitimidade no que concerne a conteúdos, já que qualquer conteúdo pode ser objeto de uma norma legítima.

Esse imbricamento entre Estado e legalidade nos remete à noção de Estado legal, cuja melhor formulação para Weber será a burocracia. O Estado regido pela legalidade é portador de algumas características peculiares. Primeiro, o seu aspecto processual, já que qualquer direito pode se criar e se modificar por meio de um estatuto sancionado corretamente quanto à forma, como visto acima. Em segundo lugar, a legalidade, já que se obedece não à pessoa em virtude de seu direito próprio, mas à regra estatuída, a qual estabelece, ao mesmo tempo, a quem e em que medida se deve obedecer, de tal forma que também o que emite uma ordem obedece a uma regra, a saber, à lei ou ao regramento de uma norma formalmente abstrata ${ }^{30}$.

Contrariando as teses de Weber expostas na Teoria da ação comunicativa de 1981, Habermas vincula, em parte do texto, a legitimidade do direito à racionalidade moral, esta última apresentada nas Notas programáticas para uma fundamentação da ética discursiva ${ }^{31}$ de 1983, sendo tal vinculação desenvolvida sistematicamente nas Tanner Lectures de 1986, e em Wie ist Legitimität durch Legalität möglich? de 1987.

No mencionado texto de 1981, Teoria da ação comunicativa, Habermas parte da análise de três características imputadas por Weber ao direito, mormente o moderno, a positividade, a legalidade e a formalidade ${ }^{32}$. Chama a atenção, particularmente com relação ao primeiro ponto, o caráter pós-tradicional do direito, ou seja, a vinculação do direito àquele estatuto positivado pelo legislador. Já com relação ao segundo aspecto, destaca-se a independência dos motivos e, portanto, uma versão processual da legitimidade e, com relação ao último, estatui-se a neutralização moral do direito.

Com o conceito de fé na legalidade, Weber estabelece um vínculo com a racionalidade que habita na forma do direito - o que legitima o poder exercido nesta forma - desvinculando a legitimidade da fé na tradição ou no carisma. "Isso significa, para Weber, que o direito dispõe de 
uma racionalidade própria, que não depende da moral"33. Ao contrário, qualquer ligação com a moral implica um risco a essa racionalidade. Como se verá, o que Habermas procurará no contexto das Tanner Lectures será negar esta tese, a saber, que a racionalidade da forma jurídica seja independente da moral, ao passo que em FG ele restabelecerá - em termos - a tese de Weber, sem, no entanto, despedir a moral tout court.

Essa neutralização moral do direito em conjunção com uma concepção decisionista do mesmo, como dito, é a questão que Habermas quer criticar. O ponto está em que, sendo controversos os princípios substantivos de moralidade, como natureza e razão, Weber - na interpretação de Habermas - une uma concepção positivista de procedimento ${ }^{34}$ que engendra a legitimidade com um conceito decisionista ${ }^{35}$ dos conteúdos.

Nesse particular cabe um esclarecimento sobre o que significa ser positivista e decisionista. Habermas define o decisionismo como um ato discricionário ${ }^{36}$ ou como aquele que decide sem fundamentos ${ }^{37}$. Já o positivismo, para ele, é aquela posição que privilegia a segurança sobre a correção ${ }^{38}$. Fazendo uso da terminologia introduzida por Dworkin que distingue princípios de regras, o positivista é o que nega tal distinção, tendo por conseqüência a redução de todas as normas jurídicas a regras, o que determina, em não havendo princípios, que se tenha que decidir discricionariamente no caso de lacuna das regras. Nesse caso, o positivista é um decisionista $^{39}$. Habermas, por seu turno, quer evitar ambos, ou seja, um conceito positivista de procedimento, bem como uma concepção decisionista dos conteúdos.

\section{Crítica de Habermas a Weber}

No sentido apontado acima, a argumentação de Habermas consiste em mostrar como em Weber já opera implicitamente um tipo de racionalidade para além daquela instrumental por ele explicitamente admitida, a qual estaria na base da própria justificação da legalidade. Ele analisa dois pontos centrais da teoria weberiana nos quais isso ocorreria. O primeiro se refere à definição de ação social e o segundo à definição de legitimidade do direito. Em ambos os momentos, Habermas quer flagrar a racionalidade comunicativa operando implicitamente na argumentação weberiana.

Com relação ao primeiro ponto, de fato, Weber define "ação" do seguinte modo: "por 'ação' se deve entender uma conduta humana [...] sempre que o sujeito ou sujeitos da ação unam 
a ela um sentido subjetivo" ${ }^{40}$. O ponto de Habermas é que ele, para introduzir o conceito de ação social, não pode fazê-lo somente com a definição acima que Habermas avalia em sua terminologia como monológica e intencionalista, portanto devedora do paradigma da consciência, o qual implica certo grau de solipsismo. Por isso, Weber tem que fazer duas determinações a mais que extrapolariam o limite de sua definição, determinações essas que poriam em operação elementos de uma racionalidade comunicativa obliterada no texto explícito. Nesse sentido, vejase agora a definição de ação social: “a 'ação social', portanto, é uma ação na qual o sentido mentalizado por um sujeito ou sujeitos está referido à conduta de outros, orientando-se por esta em seu desenvolvimento" ${ }^{41}$. Ou seja, a ação social se orienta pelas ações dos outros ${ }^{42}$. Além disso, ele acrescenta: “por ‘relação' social se deve entender uma conduta plural - de vários - que, pelo sentido que encerra, se apresenta como reciprocamente 'referida', orientando-se por essa reciprocidade" ${ }^{43}$. Assim, ele não consegue introduzir o conceito de ação social como uma explicação do conceito de sentido subjetivo tal qual declinado na definição básica de ação, mas se vê na necessidade de completar o modelo da ação teleológica com duas determinações a mais para que se possam cumprir as condições para definir uma ação como social, a saber, (a) a orientação em função do comportamento dos outros e (b) a relação reflexiva entre as orientações para ação, ou seja, deverão ser ações reciprocamente referidas ${ }^{44}$.

No caso do direito, Weber define a legitimidade da legalidade do seguinte modo: "esta legalidade pode valer como legítima: (a) em virtude de um pacto dos interessados; (b) em virtude de uma imposição [Oktroyierung] por uma autoridade considerada legítima e da correspondente obediência" ${ }^{\text {45 }}$. Em qualquer uma dessas formulações, a fonte da legitimidade não é a legalidade enquanto tal - acusa Habermas -, mas, no primeiro caso, um acordo, um pacto, e no segundo uma autoridade já considerada legítima. Como se sabe, os dois critérios se mesclam, pois nunca um pacto é unânime, sendo as regras da maioria impostas à minoria pela autoridade legítima resultante da maioria. De qualquer modo, a fonte de legitimidade não é a legalidade como tal, mas o acordo. Aponta-se, assim, para a insuficiência do critério formal legal de correção do direito, buscando uma fundamentação de outro tipo, de tal modo que "a fé na legalidade de um procedimento não pode engendrar per se legitimidade, isto é, somente pela virtude da correção processual do procedimento estabelecido positivamente" ${ }^{, 46}$.

Em FG é registrada, ademais, a insuficiência filosófica de Weber, haja vista este não ter distinguido corretamente entre si três termos importantes: doutrina legal, teoria legal e filosofia 
do direito. Na verdade, Habermas está reclamando pela negligência de Weber com relação à última, o que se deveu, sugere ele, ao ceticismo weberiano quanto à possibilidade de uma moral cognitivista $^{47}$. De fato, para Weber, "os critérios materiais para julgar o que é legítimo em sentido jusnaturalista são a 'natureza' e a 'razão",48. No entanto, a tônica de seu pensamento é absolutamente crítica de tal possibilidade: "o conceito de racionalidade material é completamente equívoco" $" 49$. Nessa classe da equivocidade ele nomina as exigências éticas, a igualdade, a utilidade, em suma, a própria racionalidade moral.

\section{O modelo das Tanner Lectures (1986)}

Interessantemente, no contexto das Tanner Lectures, Habermas defende - contra Weber a tese de que a legitimidade não resulta das características formais do direito, a saber, (a) do seu caráter sistemático; (b) do seu caráter abstrato e geral e (c) da segurança ${ }^{50}$ e, sim, "de implicações morais, que podem ser inferidas dessas características" $" 51$. No texto, ele faz uma minuciosa análise dos caracteres do direito que Weber considerara formais, para desmascará-los na sua natureza verdadeiramente moral. Uma acusação, aliás, que Rawls parece endereçar ao Habermas de $\mathrm{FG}^{52}$.

Portanto, as qualidades formais do direito só poderiam garantir a legitimidade "na medida em que se tivessem comprovado como "racionais' em um sentido prático moral" ${ }^{, 53}$. Habermas acusa Weber de não ter reconhecido isso devido ao seu ceticismo moral, o qual militava contra uma moral substantiva que fosse válida universalmente. No entanto, avalia Habermas, ele não levou a sério a possibilidade de uma moral cognitivista, embora formalmente considerada. Dito claramente, nas Tanner Lectures, “a legitimidade da legalidade não pode ser explicada a partir de uma racionalidade autônoma inserida na forma jurídica isenta de moral; ela resulta, ao invés disso, de uma relação interna entre direito e moral" ${ }^{15}$. Ele propõe mesmo uma fusão, um entrelaçamento [Verschränkung] de procedimentos:

\footnotetext{
a legitimidade pode ser obtida através da legalidade na medida em que os processos para a produção de normas jurídicas são racionais no sentido de uma razão prático-moral procedimental. A legitimidade da legalidade resulta do entrelaçamento entre processos jurídicos e uma argumentação moral que obedece à própria racionalidade procedimental $^{55}$.
} 
Assim, vislumbra-se, nessa relação complementar entre moral e direito, um verdadeiro entrelaçamento [Verschränkung] entre $\operatorname{ambos}^{56}$, de modo que, nas Tanner Lectures, a moral, despida de conteúdo e sublimada em procedimento, pode controlar o direito e vice-versa ${ }^{57}$. Mesmo que o direito domestique as argumentações morais pelo estabelecimento de competências, prazos, critérios, tal arquitetônica não atinge a própria lógica da argumentação moral, visto que a própria racionalidade jurídica é analisada e compreendida em termos morais, ainda que processuais. Habermas propõe claramente o padrão de um processo moral de argumentação como critério para avaliar os procedimentos jurídicos ${ }^{58}$.

Nesse sentido, a racionalidade formal do direito se torna dependente da moral ${ }^{59}$, sem que tal remoralização do direito destrua as suas qualidades formais, pois a moral é entendida em um sentido mais abstrato, qual seja, como procedimento ${ }^{60}$. Desse modo, é possível "extrair do próprio processo de legislação democrática o ponto de vista moral da imparcialidade" ${ }^{, 61}$. Tal possibilidade depende, claro, do modo como se interpreta a universalidade. Ela pode significar ou a lei geral e abstrata ou a universalidade processual que se diz no modo da aceitação por muitos ou por todos ${ }^{62}$. No último sentido, a moralidade opera dentro do processo legislativo no sentido de submetê-lo ao princípio de universalização e, portanto, ao ponto de vista moral a que se deve obedecer ao justificar normas ${ }^{63}$. A racionalidade processual incorporada pelo direito, a saber, aquela de caráter moral, é a única que pode garantir a legitimidade em um mundo pluralista.

Nas Tanner Lectures, como já mencionado, Habermas levanta as seguintes características formais que Weber imputa ao direito: (a) o caráter sistemático; (b) o caráter abstrato e geral; (c) a segurança ${ }^{64}$. Desse modo, como já propusera Weber, e conforme já foi mencionado acima, podese concluir facilmente que "a racionalidade do direito está fundamentada nas suas qualidades formais" ${ }^{\prime 65}$, o que implica a tese da sua neutralidade sob o ponto de vista moral. Tal ocorre porque

\footnotetext{
a materialização configura uma moralização do direito, isto é, a introdução de pontos de vista da justiça material no direito positivo. Disso resultou a afirmação crítica, segundo a qual, o estabelecimento de um nexo interno entre direito e moral destrói a racionalidade que habita no medium do direito enquanto tal ${ }^{66}$.
}

É desse modo que, no que concerne a (c), a segurança jurídica, pode-se perceber que ela é na verdade um valor dentre outros e que concorre com outros valores, por exemplo, com a participação em igualdade de chances no processo político e com a justiça social, até porque, neste último caso, as leis são feitas com conceitos jurídicos indeterminados, como os de saúde e 
de educação. Ou seja, às vezes se obliteram discretamente razões de segurança jurídica em nome de uma maior legitimidade ${ }^{67}$. No entanto, esses são valores concorrentes que têm que ser ponderados e decididos: "tais colisões têm que ser decididas sob o ponto de vista moral da possibilidade de universalização de interesses" ${ }^{~}$. Com relação a (b), o caráter abstrato e geral, percebe-se a sua aproximação ao princípio da igualdade perante a lei, o que corresponde ao princípio: "aquilo que é igual tem que ser tratado de modo igual e o que é diferente tem que ser tratado de modo diferente" ${ }^{\prime 69}$. Por fim, (a), o caráter sistemático é só um elemento na busca de fundamentação, a qual se torna mais premente em razão da modificabilidade do direito. Assim, o trabalho sistematizador visaria a encontrar princípios evidentes que justificariam o direito, mesmo este sendo modificável. Este caráter principiológico da sistematização aponta para uma validade pós-tradicional que não poderia se basear só nos costumes. No entanto, os princípios gerais uma vez que fossem encontrados, quando problematizados, clamariam mais, para sua fundamentação, a uma razão prática no sentido de Kant, do que a uma racionalidade científica neutra moralmente que se limitaria a encontrar e formular claramente tais princípios já operantes $^{70}$.

Como se percebe, a argumentação contra Weber aponta no sentido de moralizar o procedimento jurídico a partir da ética discursiva, a qual se autocompreende em um sentido formal. Assim, Habermas, na medida em que aceita parcialmente o ceticismo de Weber quanto à moral tradicional, também reconstrói a possibilidade de uma moral racional em um nível mais abstrato, aquele dos procedimentos, "porque a força legitimadora reside em processos que institucionalizam o caminho para o seu resgate argumentativo" ${ }^{, 71}$. Assim, o que a filosofia ausente em Weber, como mencionado - pode justificar é um procedimento que marcará os seus produtos com a legitimidade, embora não haja garantias de que isso ocorra, devido às limitações a que tais procedimentos estão submetidos.

Cabe observar que o caminho da remoralização do direito escolhido por Habermas busca evitar o que poderia se assemelhar a uma renovação do direito natural, pois este, frente a uma sociedade pluralista, teria conteúdos com premissas normativas fortes demais, de tal sorte que "somente as teorias da justiça e da moral ancoradas no procedimento prometem um processo imparcial para a fundamentação e avaliação de princípios" ${ }^{\text {"72 }}$. Ou seja, ele comunga com Weber certo ceticismo quanto à correção dos conteúdos, implicando em contrapartida que se deva analisar, como opção, o núcleo racional do procedimento. Nesse sentido, o próprio 
contratualismo ou o imperativo categórico podem ser entendidos como procedimentos: "o modelo do contrato social, do mesmo modo que o imperativo categórico, pode ser entendido como proposta para um processo, cuja racionalidade garante a correção de qualquer tipo de decisão tomada conforme um procedimento" 73 . No entanto, o procedimento não pode ele próprio ser despido de uma racionalidade prática. Weber teria sido levado a isso por não conseguir conceber uma racionalidade para além da instrumental, mas que, como visto, tal racionalidade seria operante em Weber pace ele mesmo.

Forçoso concluir, assim, que a legitimidade se deve "a um conteúdo moral implícito nas qualidades formais do direito" ${ }^{, 74}$. Tal conteúdo normativo pode ser analisado a partir da idéia de imparcialidade, pois, segundo ele, "essa idéia da imparcialidade forma o núcleo da razão prática" ${ }^{, 75}$, uma vez que ela requer que se encontre uma perspectiva que esteja acima da pluralidade das idéias de vida boa ${ }^{76}$. Por isso, teorias da justiça contratualistas, como a de Rawls, desenvolvem processos que tentam traduzir esta idéia de imparcialidade, torná-la operacional processualmente, tanto que Rawls sustenta que a posição original é um procedimento que leva à unanimidade $^{77}$, pois as diferenças entre os participantes contratantes não seriam conhecidas, o que tornaria todos igualmente racionais. Assim, haveria um imbricamento entre justiça processual pura e eqüidade ${ }^{78}$. Ele chega a afirmar que uma tal formulação não é estranha à teoria moral, por exemplo, àquela de $\mathrm{Kant}^{79}$. Habermas, nessa mesma direção, sustenta: "para saber se tal processo puro, que precede qualquer institucionalização, é racional, é necessário averiguar se nele se expressa adequadamente o moral point of view" ${ }^{\sharp 0}$. Tal padrão de racionalidade pode ser estendido para o procedimento de legislação - para o qual chamou a atenção Ely - que visa a "assegurar a consideração simétrica de todos os interesses envolvidos e de todos os aspectos relevantes de uma matéria sujeita a regulamentação" ${ }^{\text {. }}$.

Nesse sentido, ele compara os dois processos, aquele sob a forma jurídica e aquele sob a forma moral, e observa que o processo jurídico é completo, pois tem critérios independentes, externos, ditados positivamente pelo legislador, ao passo que o processo moral é incompleto, pois não tem critérios independentes, estando enclausurado em si mesmo ${ }^{82}$. Seja como for, ambos os processos têm pressupostos idealizados inevitáveis no sentido de uma coerção transcendental fraca $^{83}$, pressupostos esses que tangenciam a idéia normativa moral de imparcialidade. Seria a fragilidade da racionalidade procedimental imperfeita que clamaria pelo direito, o que Habermas traduzirá na tese da indeterminação cognitiva da moral, na tese da fraqueza da vontade e na tese 
do déficit institucional da moral. Ou seja, a imputabilidade de uma norma moral bem fundamentada depende da expectativa de que ela seja obedecida por outros, sendo que, para ele, os próprios argumentos de justificação necessitam, de alguma forma, dessa expectativa de obediência geral. Visível também na formulação anterior, a tese de uma justificação moral da própria forma jurídica que desaparecerá na obra FG. É nesse sentido, aliás, que se pode falar de uma ética da responsabilidade, já que o direito compensaria a fraqueza da moral, sob o ponto de vista externo, posto que os motivos não podem ser forçados. Inegável, nesse sentido, a vantagem da coerção e da modificabilidade do direito.

Como contraponto ao que se poderia chamar positivismo processual e decisionismo dos conteúdos, Habermas estatui o procedimento moral como padrão de correição do procedimento positivamente estabelecido, atenuando fortemente, com isso, o caráter decisionista dos produtos oriundos deste procedimento, visto que o característico do procedimento moral é o vínculo argumentativo que deve gravitacionar o ato decisório. Habermas vincula, portanto, o direito à racionalidade moral, a qual ele desenvolverá em 1983, e que se comprova em relação ao direito nas Tanner Lectures de 1986. Não que Habermas dispusesse de uma moral processual, pois a moral reside para ele no desempenho discursivo de uma das pretensões de validade, segundo um procedimento baseado no princípio de universalização que ele tentou deduzir da própria racionalidade comunicativa em 1983. No entanto, o procedimento da moral, por exigir mais do que o procedimento legal, é tal que assegura com muito mais garantia a correção de seu resultado. Nesse ponto, Habermas parece desconfiado do procedimento jurídico, diferentemente do que ocorrerá em FG, onde ele parece duvidar da possibilidade de realizar adequadamente o procedimento moral, devido, por exemplo, à indeterminação cognitiva e à fraqueza motivacional que agora não parecem mais ser domesticadas pelo direito. Quiçá esta última possa ser uma razão a aduzir a favor da desqualificação do procedimento moral como paradigma dos procedimentos jurídicos positivamente estabelecidos, visto que, de qualquer modo, o característico do procedimento moral, que é vincular a motivação, permanece opaco às determinações jurídicas.

Nas Tanner Lectures a reciprocidade do controle dos procedimentos moral e jurídico implica não só o controle moral do procedimento jurídico, mas também a domesticação daquele por parte deste, ao passo que em FG fica interditado esse controle recíproco no que concerne aos procedimentos, de tal forma que nem o processo moral é mais domesticado juridicamente, operando, portanto, com toda profundidade e exigência que lhe são próprios, e nem o 
procedimento jurídico é moralizado, sendo-lhe permitido operar com padrões próprios de legitimidade mais permissivos que os morais. No contexto pré-FG a avaliação moral era o padrão para julgar a validade jurídica; já em FG, a moral incidirá de algum modo sobre os conteúdos resultantes do princípio da democracia - esta é a tese -, sendo que este princípio agora adquire maioridade em relação à moral.

Como salientado, nas Tanner Lectures o aprofundamento moral da legitimidade jurídica é tal que as próprias condições formais da racionalidade jurídica, o gérmen da forma jurídica, são travestidas moralmente, do que ele parece claramente recuar em FG. Argumentando desse modo, a moral escrutina os procedimentos jurídicos e aí cumpre seu papel legitimatório. Portanto, há uma quase fusão entre os procedimentos jurídico e moral, posto que aquele, embora tenha critérios externos, não tem um procedimento específico. O ponto está em que precisa um procedimento específico, o moral, que possa garantir que o acordo seja racional, na medida em que possibilita a aceitação por parte de todos. Logo, não é qualquer processo que servirá, mas só o procedimento moral, e não é qualquer produto, mas só aquele oriundo do procedimento discursivo com marca moral. Em FG, a moral não escrutina o procedimento jurídico, embora este permaneça aberto às razões morais. Nem pode - frise-se - o direito suplementar a moral nesse particular. O que dá impressão de ocorrer agora na nova arquitetônica é que a moral tem seu procedimento, cujos produtos passam a vincular o legislador sob o ponto de vista normativo ainda que negativamente -, visto o procedimento moral permanecer cognitivamente melhor que o jurídico. Portanto, há uma pretendida separação entre os procedimentos, já que o jurídico, por sua natureza mesma, é mais amplo, incluindo as razões morais. No contexto da Tanner Lectures, diferentemente, não só Habermas dispõe do procedimento moral como contraponto ao positivamente estabelecido como a neutralização moral da forma jurídica operada por Weber é avaliada de forma míope em relação à sua própria possibilidade de justificação.

Cabe observar, ainda, que nas Tanner Lectures o direito já detinha a função sistêmica de complemento da fraqueza institucional da moral ${ }^{84}$, o que será potencializado em FG, mas, diferentemente do que ocorre em FG, a moral detinha a função privilegiada de justificação do direito no sentido acima explicitado, ou seja, na avaliação do procedimento juridicamente estabelecido para a produção de normas. A sua indicação na mencionada nota 4 sugere que este modo de compreender a função da moral desapareceu do empreendimento de FG e que a legitimidade jurídica passou a se estatuir de forma autônoma à moral? 


\section{Conclusão}

Considerando a posição processual de Habermas, bem como a tese da conexão entre direito e moral, podem ser apontados três modelos de apresentação da relação entre direito e moral $^{85}$. A saber:

- Modelo 1: o procedimento moral incide sobre o procedimento jurídico. Esse é o modo de proceder que se encontra nas Tanner Lectures [1986]. Cabe mencionar que o presente modelo intenta respeitar a autonomia de ambos os sistemas, pois a moral somente faria a correição dos procedimentos jurídicos, sem ditar conteúdos específicos. Esse é o modelo que foi apresentado no presente texto.

Podem, ainda, ser apresentados mais dois modelos no contexto de FG, os quais serão tratados em outras oportunidades, a saber:

- Modelo 2: os produtos do procedimento moral são vinculantes para o procedimento jurídico. Os processos jurídico e moral são separados, sendo que os produtos resultantes de ambos são relacionados como se a moral fizesse exigências conteudísticas àquilo que deveria resultar do procedimento jurídico. Ademais, os próprios produtos morais podem já entrar diretamente no procedimento jurídico, juntamente com outros argumentos. Esse é o sentido da complementaridade como explicitamente tratado em FG [1991], pois aí a moral exige positivação. Pode-se afirmar que se trata de uma complementaridade do ponto de vista do observador, segundo a qual o direito parece cumprir um papel funcional de suprir os déficits funcionais da moral.

- Modelo 3: o procedimento moral é prévio ao jurídico, tendo a função negativa de eliminar conteúdos incompatíveis com a moral. Os procedimentos moral e jurídico são separados, mas se complementam negativamente. Segundo o esquema de Habermas, os conteúdos passariam antes pelo procedimento moral para ver de sua compatibilidade com razões morais para depois adentrarem no procedimento jurídico. Habermas sugere esse modelo em FG, mas não o desenvolve. Ele parece com o modelo legislativo, no qual todos os projetos de leis passam previamente pela comissão de constituição e justiça, antes de serem encaminhados para a comissão temática específica. Aproxima-se também do modelo de controle de constitucionalidade que, embora posterior, faz o papel do 
legislador negativo, alegando com isso não ferir o estatuto democrático que a legislação deve portar. Pode-se afirmar que se trata de uma complementaridade do ponto de vista do participante, segundo a qual a moral parece cumprir um papel de suprir os déficits de legitimidade do direito. 


\section{Notas}

\section{Das abreviaturas}

\begin{tabular}{|l|l|}
\hline FG & $\begin{array}{l}\text { HABERMAS, Jürgen. Faktizität und Geltung: Beiträge zur Diskurstheorie des } \\
\text { Rechts und des demokratischen Rechtsstaats. 4. Auflage, Frankfurt am Main: } \\
\text { Suhrkamp, 1994. }\end{array}$ \\
\hline TrFG2 & $\begin{array}{l}\text { HABERMAS, Jürgen. Direito e democracia: } \text { entre faticidade e validade. [v. II]. } \\
\text { [Trad. F. B. Siebeneichler: Faktizität und Geltung: Beiträge zur Diskurstheorie des } \\
\text { Rechts und des demokratischen Rechtsstaats]. Rio de Janeiro: Tempo Brasileiro, } \\
\text { 1997. }\end{array}$ \\
\hline
\end{tabular}

${ }^{1} \mathrm{O}$ autor agradece à CAPES pela bolsa "Estágio sênior no exterior" concedida no período de agosto de 2011 a julho de 2012 para o projeto de pesquisa "As críticas de Habermas a Kant e a Hobbes", realizado junto à Aberystwyth University, Wales, UK, em colaboração com Howard Williams. O autor agradece também à UFSC e ao seu Departamento de Filosofia pelo afastamento concedido no período mencionado.

${ }^{2}$ HABERMAS, Jürgen. Direito e democracia: entre faticidade e validade. [v. I].Rio de Janeiro: Tempo Brasileiro, 1997, p. 140-1. "Denn eine Rechtsordnung kann nur legitim sein, wenn sie moralischen Grundsätzen nicht widerspricht. Dem positiven Recht bleibt, über die Legitimitätskomponente der Rechtsgeltung, ein Bezug zur Moral eingeschrieben" [HABERMAS, Jürgen. Faktizität und Geltung: Beiträge zur Diskurstheorie des Rechts und des demokratischen Rechtsstaats. 4. Auflage, Frankfurt am Main: Suhrkamp, 1994, p. 137].

${ }^{3}$ HABERMAS, Jürgen. Direito e democracia: entre faticidade e validade. [v. I].Rio de Janeiro: Tempo Brasileiro, 1997, p. 141 [HABERMAS, Jürgen. Faktizität und Geltung: Beiträge zur Diskurstheorie des Rechts und des demokratischen Rechtsstaats. 4. Auflage, Frankfurt am Main: Suhrkamp, 1994, p. 137].

${ }^{4}$ MUGUERZA, Javier. Prólogo. In: VELASCO ARROYO, Juan Carlos. La teoría discursiva del derecho: sistema jurídico y democracia em Habermas. Madrid: Centro de Estudios Políticos y Constitucionales, 2000. p. XII.

${ }^{5}$ KETTNER, Matthias. The Disappearance of Discourse Ethics in Habermas's Between Facts and Norms. IN BAYNES, Kenneth, SCHOMBERG, René von. Essays on Habermas's "Between Facts and Norms". Albany: SUNY, 2002, p. 201-218.

${ }^{6}$ HECK, José N. Razão prática: uma questão de palavras? A controvérsia Habermas/Kant sobre moral e direito. Kant e-prints. Campinas: Série 2, v. 1, n.1, 2006, p. 19-30.

${ }^{7}$ HABERMAS, Jürgen. Direito e democracia: entre faticidade e validade. [v. I].Rio de Janeiro: Tempo Brasileiro, 1997, p. 10. "Allerdings gelange ich jetzt zu einer anderen Bestimmung des komplementären Verhältnisses von Moral und Recht als noch in den Tanner Lectures" [HABERMAS, Jürgen. Faktizität und Geltung: Beiträge zur Diskurstheorie des Rechts und des demokratischen Rechtsstaats. 4. Auflage, Frankfurt am Main: Suhrkamp, 1994, p. 10].

8 "Einen wie mir scheint normativistisch überanstrengten Zugang wählt auch K.O. Apel” [HABERMAS, Jürgen. Faktizität und Geltung: Beiträge zur Diskurstheorie des Rechts und des demokratischen Rechtsstaats. 4. Auflage, Frankfurt am Main: Suhrkamp, 1994, p. 10].

9 APEL, Karl-Otto. Auseinandersetzungen in Erprobung des transzendentalpragmatischen Ansatzes. Frankfurt am Main: Suhrkamp, 1998. Tal problema se encontra no cap. 13 do referido texto, cujo título é "Auflösung der Diskursethik? Zur Architektonik der Diskursdifferenzierung in Habermas' Faktizität und Geltung. Dritter, transzendentalpragmatisch orientierter Versuch, mit Habermas gegen Habermas zu denken”. Este capítulo foi traduzido por Luiz Moreira e publicado no livro APEL, Karl-Otto, OLIVEIRA, Manfredo Araújo de, MOREIRA, Luiz. Com Habermas, contra Habermas: direito, discurso e democracia. São Paulo: Landy, 2004, p. 201-321.

ethic@-Florianópolis, v. 10,n.3,p.13-37,Dez. 2011. 
${ }^{10}$ HABERMAS, Jürgen. Direito e democracia: entre faticidade e validade. [v. II]. Rio de Janeiro: Tempo Brasileiro, 1997, p. 322, Posfácio [HABERMAS, Jürgen. Faktizität und Geltung: Beiträge zur Diskurstheorie des Rechts und des demokratischen Rechtsstaats. 4. Auflage, Frankfurt am Main: Suhrkamp, 1994, p. 677].

${ }^{11}$ HABERMAS, Jürgen. Direito e democracia: entre faticidade e validade. [v. II]. Rio de Janeiro: Tempo Brasileiro, 1997, p. 322 [HABERMAS, Jürgen. Faktizität und Geltung: Beiträge zur Diskurstheorie des Rechts und des demokratischen Rechtsstaats. 4. Auflage, Frankfurt am Main: Suhrkamp, 1994, p. 677]. Posfácio.

${ }^{12}$ LUHMANN, Niklas. Sociologia do direito I. [G. Bayer: Rechtssociologie 1]. Rio de Janeiro: Tempo Brasileiro, 1983, p. 28.

${ }^{13}$ HABERMAS, Jürgen. Theorie des kommunikativen Handelns. (Band I). Frankfurt am Main: Suhrkamp, 1981, p. $357-8$.

${ }^{14}$ Marcos Nobre sustenta que a Teoria Crítica apresenta dois requisitos: uma orientação para a emancipação e um comportamento crítico em relação ao conhecimento produzido sob as condições do sistema de produção capitalista, buscando apreender a realidade social [NOBRE, M. A idéia da teoria crítica. IN MÜLLER, Maria Cristina, CENCI, Elve Miguel. Ética, política e linguagem: confluências. Londrina: CEFIL, 2004, p. 21].

${ }^{15}$ HABERMAS, Jürgen. Teoria y práxis. Madrid: Tecnos, 1987, p. 33. Trata-se da explicitação de "um saber intuitivo, que forma um Know-How, que está dado com a competência no uso das regras" (HABERMAS, Jürgen. Teoria y práxis. Madrid: Tecnos, 1987, p. 33).

${ }^{16}$ HABERMAS, Jürgen. Vorstudien und Ergänzungen zur Theorie des Kommunikativen Handelns. Frankfurt am Main: Suhrkamp, 1984, p. 370.

${ }^{17}$ Tal tese se apresenta fortemente no texto A filosofia como guardador de lugar e como intérprete que compõe o livro HABERMAS, Jürgen. Consciência moral e agir comunicativo. (Trad. Guido A. de Almeida: Moralbewusstsein und kommunikatives Handeln). Rio de Janeiro: Tempo Brasileiro, 1989, p. 30.

${ }^{18}$ NOBRE, Marcos. A Teoria Crítica. Rio de Janeiro: Zahar, 2004, p. 57-8.

${ }^{19}$ WEBER, Max. Wirtschaft und Gesellschaft. Tübingen: Mohr, s/d, p. 16.

${ }^{20}$ WEBER, Max. Wirtschaft und Gesellschaft. Tübingen: Mohr, s/d, p. 17.

${ }^{21}$ WEBER, Max. Wirtschaft und Gesellschaft. Tübingen: Mohr, s/d, p. 28.

${ }^{22}$ WEBER, Max. Wirtschaft und Gesellschaft. Tübingen: Mohr, s/d, p. 30.

${ }^{23}$ FG p. 113.

${ }^{24}$ KELSEN, Hans. Teoria geral do direito e do Estado. São Paulo: Martins Fontes, 2000, p. 559.

${ }^{25}$ FG p. 143

${ }^{26}$ WEBER, Max. Wirtschaft und Gesellschaft. Tübingen: Mohr, s/d, p. 502s.

${ }^{27}$ WEBER, Max. Wirtschaft und Gesellschaft. Tübingen: Mohr, s/d, p. 19.

${ }^{28}$ WEBER, Max. Os três tipos puros de dominação legítima. [Coleção grandes cientistas sociais n. 13. WEBER, Max. Sociologia]. 5. ed., São Paulo: Ática, 1991, p. 128.

${ }^{29}$ WEBER, Max. Wirtschaft und Gesellschaft. Tübingen: Mohr, s/d, p. 16-7.

ethic@-Florianópolis, v. 10,n. 3, p.13 -37, Dez. 2011. 
${ }^{30}$ WEBER, Max. Os três tipos puros de dominação legítima. [Coleção grandes cientistas sociais n. 13. WEBER, Max. Sociologia]. 5. ed., São Paulo: Ática, 1991, p. 129.

${ }^{31}$ Trata-se do cap. 3 de Consciência moral e agir comunicativo.

${ }^{32}$ HABERMAS, Jürgen. Theorie des kommunikativen Handelns. (Band I). Frankfurt am Main: Suhrkamp, 1981, p. $351-2$.

${ }^{33}$ TrFG2 p. 193 [FG p. 541].

${ }^{34}$ HABERMAS, Jürgen. Theorie des kommunikativen Handelns. (Band I). Frankfurt am Main: Suhrkamp, 1981, p. $358-9$.

${ }^{35}$ HABERMAS, Jürgen. Theorie des kommunikativen Handelns. (Band I). Frankfurt am Main: Suhrkamp, 1981, p. $361-2$.

${ }^{36}$ FG p. 248.

${ }^{37}$ HABERMAS, Jürgen. Theorie des kommunikativen Handelns. (Band I). Frankfurt am Main: Suhrkamp, 1981, p. $358-9$.

${ }^{38}$ FG p. 248.

${ }^{39}$ FG p. 256. O positivismo responde a um aspecto conceitual da teoria do direito, segundo o qual "a verdade de uma proposição legal consiste em fatos acerca das regras que foram adotadas por instituições sociais específicas e nada

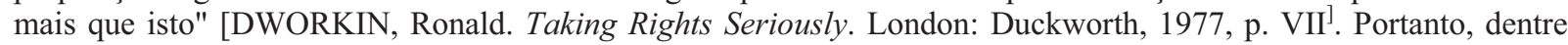
outras conseqüências, não existem direitos anteriores ao direito positivo. Calcado no princípio da segurança, o positivismo determina o encurtamento semântico das normas, operando, tecnicamente, com o conceito de regras, as quais têm uma abrangência semântica bem determinada: "Rules are applicable in an all-or-nothing fashion"; princípios têm "the dimension of weight or importance" [DWORKIN, Ronald. Taking Rights Seriously. London: Duckworth, 1977, p. 24 e 26]. Assim, o positivismo apresenta um tipo de aplicação mecânica para os casos simples e, para os casos difíceis, uma aplicação baseada na discricionariedade [discretion], sendo que onde há arbítrio do juiz não há lei: "So far as the judge's arbitrium extends, there is no law at all" [AUSTIN, John. Lectures on Jurisprudence. [V. I]. Glashütten im Taunus: Auvermann, 1972. [1. ed., 1863. p. 664].

${ }^{40}$ WEBER, Max. Wirtschaft und Gesellschaft. Tübingen: Mohr, s/d, p. 1.

${ }^{41}$ WEBER, Max. Wirtschaft und Gesellschaft. Tübingen: Mohr, s/d, p. 1.

${ }^{42}$ WEBER, Max. Wirtschaft und Gesellschaft. Tübingen: Mohr, s/d, p. 11.

${ }^{43}$ WEBER, Max. Wirtschaft und Gesellschaft. Tübingen: Mohr, s/d, p. 13.

${ }^{44}$ HABERMAS, Jürgen. Theorie des kommunikativen Handelns. (Band I). Frankfurt am Main: Suhrkamp, 1981, p. 378.

${ }^{45}$ WEBER, Max. Wirtschaft und Gesellschaft. Tübingen: Mohr, s/d, p. 19.

${ }^{46}$ HABERMAS, Jürgen. Theorie des kommunikativen Handelns. (Band I). Frankfurt am Main: Suhrkamp, 1981, p. 360 .

${ }^{47}$ FG p. 95.

${ }^{48}$ WEBER, Max. Wirtschaft und Gesellschaft. Tübingen: Mohr, s/d, p. 497.

ethic@-Florianópolis, v.10,n.3,p.13-37, Dez. 2011. 


\footnotetext{
${ }^{49}$ WEBER, Max. Wirtschaft und Gesellschaft. Tübingen: Mohr, s/d, p. 45.

${ }^{50}$ WEBER, Max. Wirtschaft und Gesellschaft. Tübingen: Mohr, s/d, p. 504.

${ }^{51}$ HABERMAS, Jürgen. Direito e democracia: entre faticidade e validade. [v. II]. Rio de Janeiro: Tempo Brasileiro, 1997, p. 198 [HABERMAS, Jürgen. Faktizität und Geltung: Beiträge zur Diskurstheorie des Rechts und des demokratischen Rechtsstaats. 4. Auflage, Frankfurt am Main: Suhrkamp, 1994, p. 547].
}

52 "I see my reply as a defense of liberalism since any liberal view must be substantive, and it is correct in being so. Moreover, I do not see why Habermas's view is not also substantive, even though the substantive elements may differ" [RAWLS, John. Political Liberalism. New York: Columbia University Press, 1996, p. 421]. Por "substância" Rawls entende, no presente contexto, valores morais como a imparcialidade, como se verá adiante.

${ }^{53}$ HABERMAS, Jürgen. Direito e democracia: entre faticidade e validade. [v. II]. Rio de Janeiro: Tempo Brasileiro, 1997, p. 200-1 [HABERMAS, Jürgen. Faktizität und Geltung: Beiträge zur Diskurstheorie des Rechts und des demokratischen Rechtsstaats. 4. Auflage, Frankfurt am Main: Suhrkamp, 1994, p. 549].

${ }^{54}$ HABERMAS, Jürgen. Direito e democracia: entre faticidade e validade. [v. II]. Rio de Janeiro: Tempo Brasileiro, 1997, p. 202 [HABERMAS, Jürgen. Faktizität und Geltung: Beiträge zur Diskurstheorie des Rechts und des demokratischen Rechtsstaats. 4. Auflage, Frankfurt am Main: Suhrkamp, 1994, p. 550].

${ }^{55}$ HABERMAS, Jürgen. Direito e democracia: entre faticidade e validade. [v. II]. Rio de Janeiro: Tempo Brasileiro, 1997, p. 203 [HABERMAS, Jürgen. Faktizität und Geltung: Beiträge zur Diskurstheorie des Rechts und des demokratischen Rechtsstaats. 4. Auflage, Frankfurt am Main: Suhrkamp, 1994, p. 552].

${ }^{56}$ HABERMAS, Jürgen. Faktizität und Geltung: Beiträge zur Diskurstheorie des Rechts und des demokratischen Rechtsstaats. 4. Auflage, Frankfurt am Main: Suhrkamp, 1994, p. 568.

57 "De sorte que o direito [Verfahrensrecht] e a moral procedimentalizada podem controlar-se mutuamente" [HABERMAS, Jürgen. Direito e democracia: entre faticidade e validade. [v. II]. Rio de Janeiro: Tempo Brasileiro, 1997, p. 218 [HABERMAS, Jürgen. Faktizität und Geltung: Beiträge zur Diskurstheorie des Rechts und des demokratischen Rechtsstaats. 4. Auflage, Frankfurt am Main: Suhrkamp, 1994, p. 568]].

${ }^{58}$ HABERMAS, Jürgen. Faktizität und Geltung: Beiträge zur Diskurstheorie des Rechts und des demokratischen Rechtsstaats. 4. Auflage, Frankfurt am Main: Suhrkamp, 1994, p. 570.

59 “A legitimidade da legalidade não pode ser explicada a partir de uma racionalidade autônoma inserida na forma jurídica isenta de moral; ela resulta, ao invés disso, de uma relação interna entre direito e moral" [HABERMAS, Jürgen. Direito e democracia: entre faticidade e validade. [v. II]. Rio de Janeiro: Tempo Brasileiro, 1997, p. 202 [HABERMAS, Jürgen. Faktizität und Geltung: Beiträge zur Diskurstheorie des Rechts und des demokratischen Rechtsstaats. 4. Auflage, Frankfurt am Main: Suhrkamp, 1994, p. 550]].

${ }^{60}$ HABERMAS, Jürgen. Faktizität und Geltung: Beiträge zur Diskurstheorie des Rechts und des demokratischen Rechtsstaats. 4. Auflage, Frankfurt am Main: Suhrkamp, 1994, p. 571.

${ }^{61}$ HABERMAS, Jürgen. Direito e democracia: entre faticidade e validade. [v. II]. Rio de Janeiro: Tempo Brasileiro, 1997, p. 244 [HABERMAS, Jürgen. Faktizität und Geltung: Beiträge zur Diskurstheorie des Rechts und des demokratischen Rechtsstaats. 4. Auflage, Frankfurt am Main: Suhrkamp, 1994, p. 596].

${ }^{62}$ Ver a esse respeito VOLPATO DUTRA, Delamar José. Kant e Habermas: a reformulação discursiva da moral kantiana. Porto Alegre: EDIPUCRS, 2002. 
${ }^{63}$ HABERMAS, Jürgen. Faktizität und Geltung: Beiträge zur Diskurstheorie des Rechts und des demokratischen Rechtsstaats. 4. Auflage, Frankfurt am Main: Suhrkamp, 1994, p. 597. Ver a esse respeito VOLPATO DUTRA, Delamar José. O acesso comunicativo ao ponto de vista moral. Síntese Nova Fase. V. 25, n. 83, 1998, p. 509-526.

${ }^{64}$ WEBER, Max. Wirtschaft und Gesellschaft. Tübingen: Mohr, s/d, p. 504.

${ }^{65}$ TrFG2 p. 197 [FG p. 545].

${ }^{66}$ TrFG2 p. 197 [FG p. 547]. O próprio Weber constata como o direito natural formal, por exemplo aquele do modelo contratualista, se transformou progressivamente em direito natural substantivo, a partir de determinações sociais e econômicas, como é o caso do socialismo ou das posições regulamentadoras e limitadoras da vontade contratual negocial. Tal é o caso da tese da exploração do Estado de necessidade na lei da usura, a qual proíbe juros elevados, e a nulidade das cláusulas contratuais leoninas [WEBER, Max. Wirtschaft und Gesellschaft. Tübingen: Mohr, s/d, p. 506]. Tais limitações ao formalismo só podem ser feitas, segundo ele, a partir de determinações materiais, ligadas, não ao mundo jurídico, mas ao mundo ético, o qual, como sabemos, porta, para Weber, uma certa dose de irracionalidade por remeter sempre a uma moral tradicional.

${ }^{67}$ Veja-se a esse respeito THEODORO JÚNIOR, Humberto, FARIA, Juliana Cordeiro de. A coisa julgada inconstitucional e os instrumentos processuais para seu controle. Revista dos tribunais. São Paulo: ano 91, v. 795, jan de 2002, p. 21-40.

${ }^{68}$ TrFG2 p. 199 [FG p. 547].

${ }^{69}$ TrFG2 p. 200 [FG p. 548].

${ }^{70}$ TrFG2 p. 200 [FG p. 548-9].

${ }^{71}$ TrFG2 p. 214 [FG p. 563].

${ }^{72}$ TrFG2 p. 213 [FG p. 562-3].

${ }^{73}$ TrFG2 p. 201-2 [FG p. 550].

${ }^{74}$ TrFG2 p. 214 [FG p. 563].

${ }^{75}$ TrFG2 p. 214 [FG p. 563].

76 "Impartiality asks us to find a perspective that stands above competing ideas of the good life and worthwhile ends; in this sense, right has priority over the good" [CHAMBERS, Simone. Reasonable Democracy: Jürgen Habermas and the Politics of Discourse. Ithaca: Cornell University Press, 1996, p. 19].

${ }^{77}$ RAWLS, John. A Theory of Justice. [Revised Edition]. Oxford: Oxford University Press, 1999, p. 118; RAWLS, John. Justiça como eqüidade: uma reformulação. São Paulo: Martins Fontes, 2003, p. 122].

${ }^{78}$ RAWLS, John. A Theory of Justice. [Revised Edition]. Oxford: Oxford University Press, 1999, p. 104.

${ }^{79}$ RAWLS, John. A Theory of Justice. [Revised Edition]. Oxford: Oxford University Press, 1999, p. 120, 233.

${ }^{80}$ TrFG2 p. 214 [FG p. 564].

${ }^{81}$ TrFG2 p. 220 [FG p. 570].

${ }^{82}$ FG p. 565.

${ }^{83}$ FG p. 565.

ethic@-Florianópolis, v. 10, n. 3, p. 13 -37, Dez. 2011. 
${ }^{84}$ FG p. 566-7.

${ }^{85}$ Ver a esse respeito VOLPATO DUTRA, Delamar José; LOIS, C. C. Modelos de moralização do direito: um estudo a partir de Habermas. Seqüência. V. 55, 2007, p. 233-252. 


\section{Referências Bibliográficas}

APEL, Karl-Otto, OLIVEIRA, Manfredo Araújo de, MOREIRA, Luiz. Com Habermas, contra Habermas: direito, discurso e democracia. São Paulo: Landy, 2004, p. 201-321.

APEL, Karl-Otto. Auseinandersetzungen in Erprobung des transzendentalpragmatischen Ansatzes. Frankfurt am Main: Suhrkamp, 1998.

AUSTIN, John. Lectures on Jurisprudence. [V. I]. Glashütten im Taunus: Auvermann, 1972 [1. ed., 1863].

DWORKIN, Ronald. Taking Rights Seriously. London: Duckworth, 1977.

HABERMAS, Jürgen. Consciência moral e agir comunicativo. (Trad. Guido A. de Almeida: Moralbewusstsein und kommunikatives Handeln). Rio de Janeiro: Tempo Brasileiro, 1989.

HABERMAS, Jürgen. Direito e democracia: entre faticidade e validade. [v. I]. Rio de Janeiro: Tempo Brasileiro, 1997.

HABERMAS, Jürgen. Faktizität und Geltung: Beiträge zur Diskurstheorie des Rechts und des demokratischen Rechtsstaats. 4. Auflage, Frankfurt am Main: Suhrkamp, 1994.

HABERMAS, Jürgen. Teoria y práxis. Madrid: Tecnos, 1987.

HABERMAS, Jürgen. Theorie des kommunikativen Handelns. (Band I). Frankfurt am Main: Suhrkamp, 1981.

HABERMAS, Jürgen. Vorstudien und Ergänzungen zur Theorie des Kommunikativen Handelns. Frankfurt am Main: Suhrkamp, 1984.

HECK, José N. Razão prática: uma questão de palavras? A controvérsia Habermas/Kant sobre moral e direito. Kant e-prints. Campinas: Série 2, v. 1, n.1, 2006, p. 19-30.

KELSEN, Hans. Teoria geral do direito e do Estado. São Paulo: Martins Fontes, 2000.

KETTNER, Matthias. The Disappearance of Discourse Ethics in Habermas's Between Facts and Norms. IN BAYNES, Kenneth, SCHOMBERG, René von. Essays on Habermas's "Between Facts and Norms". Albany: SUNY, 2002, p. 201-218.

LUHMANN, Niklas. Sociologia do direito I. [G. Bayer: Rechtssociologie 1]. Rio de Janeiro: Tempo Brasileiro, 1983.

MUGUERZA, Javier. Prólogo. In: VELASCO ARROYO, Juan Carlos. La teoría discursiva del derecho: sistema jurídico y democracia em Habermas. Madrid: Centro de Estudios Políticos y Constitucionales, 2000.

ethic@-Florianópolis, v. 10,n.3,p.13-37, Dez. 2011. 
NOBRE, M. A idéia da teoria crítica. IN MÜLLER, Maria Cristina, CENCI, Elve Miguel. Ética, política e linguagem: confluências. Londrina: CEFIL, 2004.

NOBRE, Marcos. A Teoria Crítica. Rio de Janeiro: Zahar, 2004, p. 57-8.

RAWLS, John. A Theory of Justice. [Revised Edition]. Oxford: Oxford University Press, 1999.

RAWLS, John. Justiça como eqüidade: uma reformulação. São Paulo: Martins Fontes, 2003.

RAWLS, John. Political Liberalism. New York: Columbia University Press, 1996.

REPA, LUIZ. A normatividade do discurso em Habermas: Sobre a neutralidade do princípio do discurso em relação ao direito e à moral. DoisPontos. V. 5, n. 2, 2008, p. 89-111.

VOLPATO DUTRA, Delamar José. Kant e Habermas: a reformulação discursiva da moral kantiana. Porto Alegre: EDIPUCRS, 2002.

VOLPATO DUTRA, Delamar José. O acesso comunicativo ao ponto de vista moral. Síntese Nova Fase. V. 25, n. 83, 1998, p. 509-526.

VOLPATO DUTRA, Delamar José; LOIS, C. C. Modelos de moralização do direito: um estudo a partir de Habermas. Seqüência. V. 55, 2007, p. 233-252.

WEBER, Max. Os três tipos puros de dominação legítima. [Coleção grandes cientistas sociais n. 13.

WEBER, Max. Sociologia. 5. ed., São Paulo: Ática, 1991.

WEBER, Max. Wirtschaft und Gesellschaft. Tübingen: Mohr, s/d. 